\title{
A new troglomorphic species of Harmonicon (Araneae, Mygalomorphae, Dipluridae) from Pará, Brazil, with notes on the genus
}

\author{
Denis Rafael Pedroso ${ }^{1, \dagger}$, Renner Luiz Cerqueira Baptista ${ }^{2, \neq}$
}

I Laboratório de Aracnologia, Departamento de Invertebrados, Museu Nacional / Universidade do Brasil (UFRJ). Quinta da Boa Vista, São Cristóvão, 20.940-040, Rio de Janeiro, RJ, Brazil 2 Laboratório de Diversidade de Aracnídeos, Instituto de Biologia, Universidade do Brasil (UFRJ)

† http://zoobank.org/E67DAD82-2E69-4E76-B4F0-7BA09E13A68F

† http://zoobank.org/CF514365-072A-4248-AF23-C112FC360305

Corresponding author: Denis Rafael Pedroso (drbpedroso@gmail.com)

Academic editor: C. Rheims | Received 26 November 2013 | Accepted 6 March 2014 | Published 14 March 2014

http://zoobank.org/EC09D20A-A46D-4F6D-BB38-0911C91CC6DF

Citation: Pedroso DR, Baptista RLC (2014) A new troglomorphic species of Harmonicon (Araneae, Mygalomorphae, Dipluridae) from Pará, Brazil, with notes on the genus. ZooKeys 389: 77-88. doi: 10.3897/zookeys.389.6693

\begin{abstract}
A new species of Harmonicon F. O. Pickard-Cambridge, 1896 (Araneae, Dipluridae) is described, from a medium-sized lateritic cave in Parauapebas, Pará, Brazil. The male holotype and only specimen known of H. cerberus sp. n. was found near the entrance of Pequiá cave. This taxon is the fourth species described and the southernmost record for the genus. The new species displays some troglomorphic characteristics, such as reduction and merging of the posterior median and both pairs of lateral eyes and pale yellow to light brown coloration. Both characters are diagnostic when compared to the normal separated eyes and reddish to dark brown of other Harmonicon species. Other diagnostic characteristics are isolated, long, rigid setae distal to the lyra and the shape of the copulatory bulb. This is the second troglomorphic mygalomorph species from Brazil and the first from the Amazonian region.
\end{abstract}

\section{Keywords}

Amazonia, biodiversity, cave, Diplurinae, Neotropics, taxonomy

Copyright D.R. Pedroso, R.L.C. Baptista. This is an open access article distributed under the terms of the Creative Commons Attribution International License (CC BY 4.0), which permits unrestricted use, distribution, and reproduction in any medium, provided the original author and source are credited. 


\section{Introduction}

Harmonicon F. O. Pickard-Cambridge, 1896 is a Neotropical genus of Mygalomorphae, belonging to the family Dipluridae. There are three described species from the Amazon region (Platnick 2014): H. audeae Maréchal \& Marty, 1998 (males and females, from Sinnamary, French Guiana), H. oiapoqueae Drolshagen \& Bäckstam, 2011 (males and females, from Saint Georges, French Guiana), and H. rufescens F. O. P.-Cambridge, 1896 (immature, from Santarém, Pará state, Brazil). This genus was removed from former synonymy with Diplura C. L. Koch, 1850 by Maréchal and Marty (1998), and it was recently placed in Diplurinae by Drolshagen and Bäckstam (2011), due to the presence of a lyra. In the family Dipluridae, this structure is known only in two other genera of that subfamily, Diplura and Trechona C. L. Koch, 1850.

The new species was found in the entrance of Pequiá cave, a medium-sized lateritic cave in the Floresta Nacional de Carajás, Parauapebas, Pará, Brazil. One of approximately 1,100 caves in iron ore deposits found in Carajás, Pequiá cave is situated at $06^{\circ} 05^{\prime} 15^{\prime \prime}$ S; 5007'13"W (DMS), circa $427 \mathrm{~m}$ above sea level (IBAMA 2003, Piló and Auler 2009, IPHAN 2013). This cave has a projection of approximately $72 \mathrm{~m}$, an L-shaped form, and contains a permanent water pool covered with guano (IBAMA 2003, Magalháes 2012, IPHAN 2013). Pequiá cave harbors important remains of earlier indigenous occupation in the Amazon region (IBAMA 2003, Magalhães 2012, IPHAN 2013).

There are several studies on the cave fauna of the iron ore cave region of Carajás (ex. Cunha et al. 2007, Pellegrini and Ferreira 2011, Prous et al. 2011). Several troglobitic species have been found in these iron ore caves, including a beetle and a centipede (Trajano and Bichuette 2010; Pellegrini and Ferreira 2011). There is a high potential of iron caves as habitat of troglobitic invertebrates in Brazil (Trajano and Bichuette 2010). As determined by Prous et al. (2011), there are an average of 2.5 troglobitic species in each cave with permanent water bodies in the Carajás region.

This is the second troglomorphic mygalomorph species from Brazil, but the first species from the Amazonian region. Recently, a troglobitic Theraphosidae was described from Bahia state (Bertani et al. 2013). Troglobitic or troglomorphic Dipluridae are common in subfamilies other than Diplurinae (ex. Euagriinae, see Coyle 1988), but the only other diplurine described solely from caves is Linothele cavicola Goloboff, 1994. This species lacks most of the modifications commonly associated with cave life, such as pigmentation and eye reduction, but displays elongated appendages, a reduced number of teeth on tarsal claw, and does not spin webs (Goloboff 1994).

\section{Methods}

The color pattern was based on a specimen preserved in $75 \%$ ethanol. Observations, photographs and measurements were made with an Olympus stereoscopic microscope. Measurements are given in millimeters, unless otherwise noted. Cephalothorax length was measured from the posterior border to the anterior margin of the clypeus. Total 
length was measured from the posterior border of the anal tubercle to the anterior margin of the clypeus, not including the spinnerets. Each article of the pedipalp and legs was measured in retrolateral view, from the basal condylus to the distal one. Photographs were taken with a Sony Cybershot DSC-V1 camera attached to the stereomicroscope. The software package COMBINEZ, version COMBINEZP (Hadley 2013), was used to create composite images with extended depth of field. Geographical coordinates for localities were obtained from GEONAMES (2013). The distribution map was elaborated using ESRI ARCGIS 10 software.

The following abbreviations are used: ALE $=$ anterior lateral eyes; $\mathrm{AME}=$ anterior median eyes; ITC $=$ inferior (or unpaired) tarsal claws; PLE $=$ posterior lateral eyes; $\mathrm{PLS}=$ posterior lateral spinnerets; $\mathrm{PME}=$ posterior median eyes; $\mathrm{PMS}=$ posterior median spinnerets; STC = superior (or paired) tarsal claws. Spines (or macroseta): ap $=$ apical; $\mathrm{p}=$ prolateral; $\mathrm{pld}=$ prolaterodorsal; $\mathrm{plv}=$ prolateroventral; $\mathrm{r}=$ retrolateral; $\mathrm{rld}=$ retrolaterodorsal; $\mathrm{rlv}=$ retrolateroventral; $\mathrm{v}=$ ventral; $\mathrm{MNRJ}=$ Museu Nacional, Universidade do Brasil/Universidade Federal do Rio de Janeiro, Brazil.

\section{Taxonomy}

\section{Harmonicon F. O. P. Cambridge, 1896}

Harmonicon F. O. P.-Cambridge, 1896: 755; Maréchal and Marty 1998: 500; Drolshagen and Bäckstam 2011: 91; Platnick 2014.

\section{Harmonicon cerberus sp. $\mathrm{n}$.}

http://zoobank.org/9AE08814-D3FA-4DCC-9F8E-1493D6CE7E13

http://species-id.net/wiki/Harmonicon_cerberus

Figs 1-11, Map 1, Table 1

Diagnosis. This species may be easily recognized by the fusion of the PME and all lateral eyes (Figs 1-3), elongated chelicerae, and pale coloration (Figs 1-2). Another diagnostic trait is the strongly thickened setae near the lyra (Fig. 6). In other Harmonicon, similar setae are found, but they are never so thickened. In prolateral view, the globose bulb, with a strong constriction around the basis of the embolus, resembles $H$. oiapoqueae, in contrast to the piriform bulb, regularly tapering toward the embolus, in $H$. audeae. The embolus is slightly longer than the bulb itself (ratio 1.3), similar to $H$. audeae (1.2), but shorter than in H. oiapoqueae (1.6).

Type material. Male holotype from Brazil: Pará: Parauapebas, Floresta Nacional de Carajás, Pequiá Cave, near entrance, September 2003, Bittencourt, R. (MNRJ 04319).

Etymology. The specific epithet "cerberus" is an apposition noun and a reference to the three-headed watchdog that guards the entrance to the underworld, the Hades, in Greek mythology. 

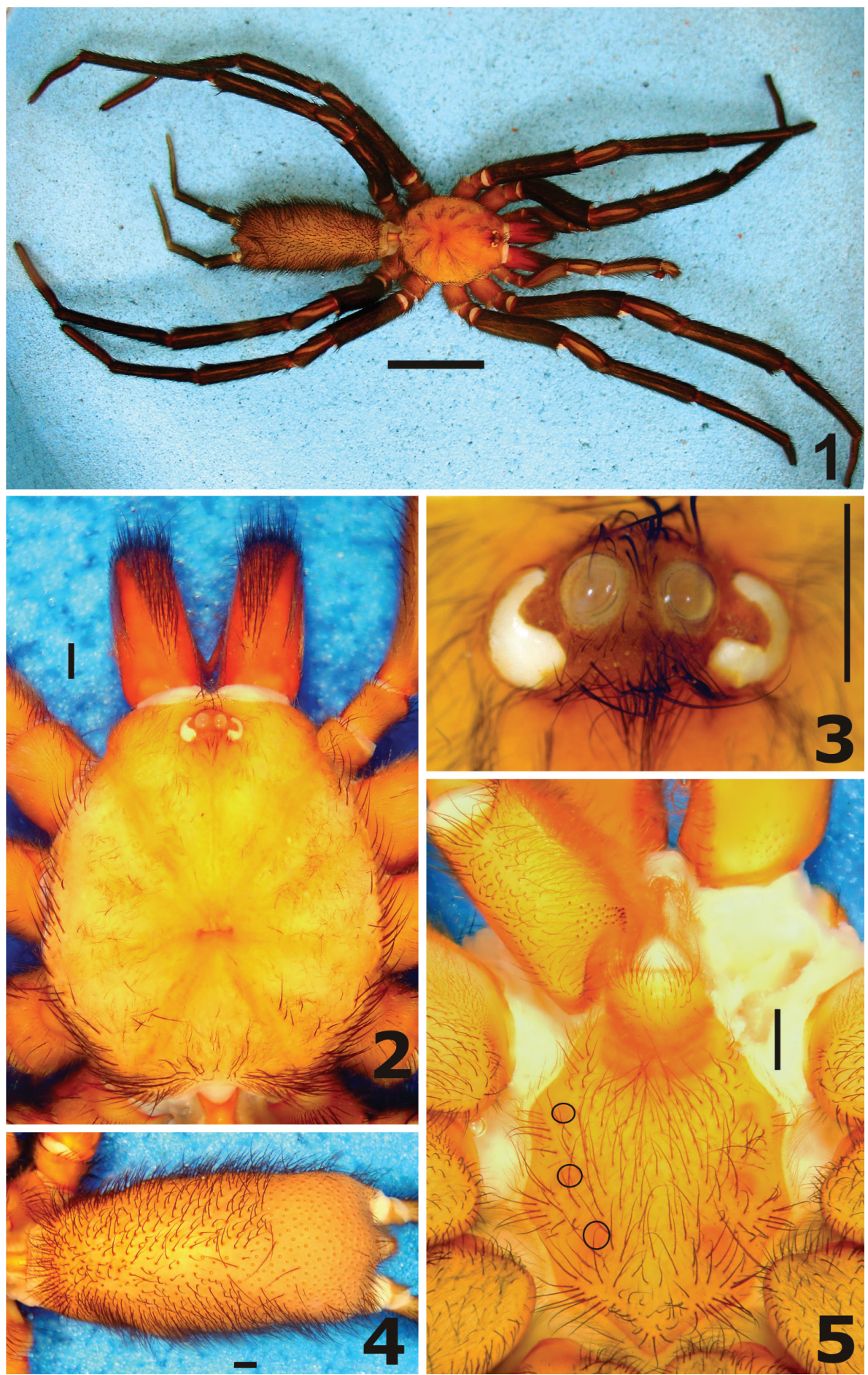

Figures I-5. Harmonicon cerberus sp. n. Male holotype: I habitus $\mathbf{2}$ carapace, dorsal view $\mathbf{3}$ eyes, dorsal view $\mathbf{4}$ abdomen, dorsal view $\mathbf{5}$ sternum, ventral view. 
Table I. Harmonicon cerberus sp. n. male holotype. Length of leg articles.

\begin{tabular}{c|c|c|c|c}
\hline & Leg I & Leg II & Leg III & Leg IV \\
\hline $\mathbf{F e}$ & 13.2 & 12.1 & 11.2 & 13.6 \\
\hline $\mathbf{P a}$ & 5.7 & 4.9 & 4.7 & 5.0 \\
\hline $\mathbf{T i}$ & 10.2 & 9.9 & 9.4 & 11.9 \\
\hline $\mathbf{M t}$ & 13.8 & 11.9 & 13.1 & 17.2 \\
\hline $\mathbf{T a}$ & 9.3 & 8.8 & 8.0 & 10.0 \\
\hline Total & 52.2 & 47.6 & 46.4 & 57.7 \\
\hline
\end{tabular}

Description. Male (holotype, Figs 1-11). Measurements: carapace 10.7 long, 9.3 wide, chelicerae 4.4. Abdomen 14.5 long, 6.6 wide. Spinnerets: PMS 2.1 long, 2.0 apart; PLS, total length 18.1, basal article 4.9, middle 6.2, distal 7.0, 2.0. apart; respectively. Legs: see Table 1.

Carapace (Figs 1,2) length/width 1.15; flat, cephalic area slightly raised, thoracic furrows shallow and wide. Fovea: 1.0 wide; deep, straight. Carapace with many short, thin setae, interspersed with some longer and thicker setae; border with abundant long and thick setae pointing out, increasing in number towards posterior angles. $\mathrm{Cl}-$ ypeus 0.3 , frontal margin bearing 9 thick, long, erect setae (Fig. 3). Eye tubercle (Fig. 3) length 0.9, width 1.9, with sparse thin setae separating eyes of both sides and thicker, longer setae at the anterior and posterior borders. AME elliptical, with a milky lens, yellowish brown background, no retina or eye pigments visible. Left AME larger than right one. All other eyes (ALE, PME and PLE) fused in an asymmetrical, crescent shaped, lateral eye mass, with irregular borders, covered by a thin lens, with uniform white background. Right lateral eye mass thinner, shorter and with a more pronounced notch than the left one. Eye row curvature not definable, but AME anterior border a little advanced in relation to anterior border of lateral eye mass (Fig 3). Right AME 0.3, AME-AME 0.3, right lateral eye mass 0.6 long. Chelicerae (Fig. 2) length/carapace length $0.41,11$ and 12 teeth on promargin, on the left and right chelicera, respectively. Maxillae (Figs 5, 6) length/width: 2.1. Cuspules: 36 spread over ventral inner heel. Lyra at the ventral side of the maxilla, asymmetrical, formed by $4-5$ modified thick, long setae, increasing in size from basal to distal one, strongly curved at apical portion, apex just tapering to a point. Right lyra with just 4 setae, left lyra with 5 large setae and a very small, thinner basal one. Thick, erect, regularly curved setae (Fig. 6, arrow) placed distally and a bit internally in relation to lyra, in number of 4 at the right maxilla and 3 at the left one. Labium: length/width 0.8 , no cuspules. Labio-sternal groove deep, with elongated sigilla. Sternum (Fig. 5) length (up to labium border) 5.3, width 4.7. Posterior angle in a blunt point, not separating coxae IV. Sigilla: three pairs, elliptical, increasing in size backwards, all far from margin by its own size. Palp long, without spines at retrolateral side, one prolateral spine at distal third of femur, 2 prolateral spines at tibia, distal one longer and thicker. Tibia: length 6.3, thin and long, with similar diameter throughout, length/width 9.1. Leg formula 4123. Legs covered with more abundant short, thin, horizontal black setae and with 


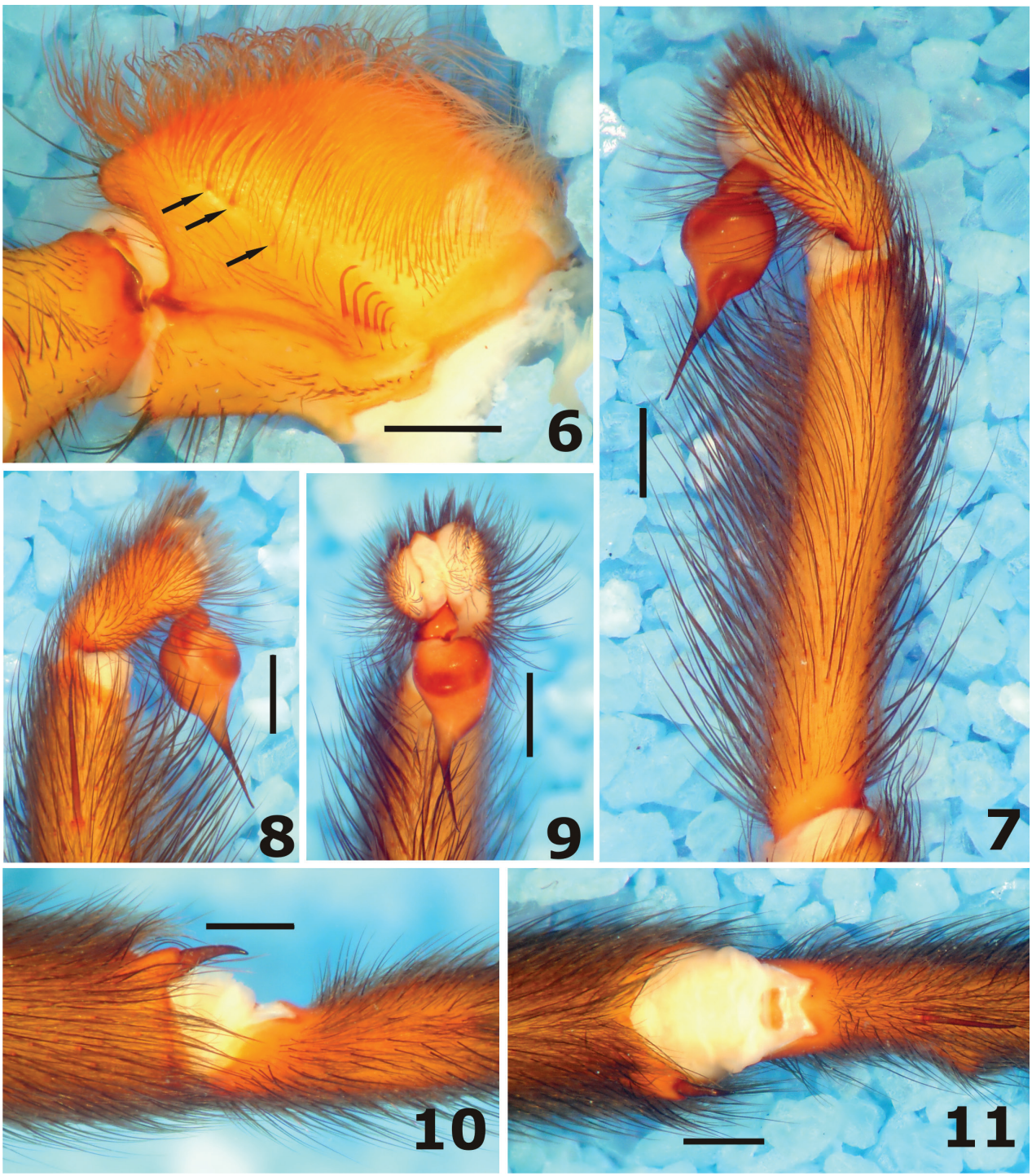

Figures 6-I I. Harmonicon cerberus sp. n. Male holotype: $\mathbf{6}$ maxillae and lyra, ventral view $\mathbf{7}$ palp and bulb, retrolateral view; copulatory bulb $\mathbf{8}$ prolateral view $\mathbf{9}$ frontal view; tibia and metatarsus of leg I I 0 retrolateral view I I ventral view.

many longer, thicker, erect black setae. Leg I with modified tibia and metatarsus, forming a retrolateral clasping mechanism (Figs 10-11). Tibia I with a retrolateral distal spur (or apophysis) relatively long, somewhat curved, blunt, bearing a curved, pointed spine at tip. Metatarsus I with small retrolateral tubercle, situated distally to basis of first ventral spine. Tarsal trichobothria much longer than covering setae, placed in a row along the midline of dorsal face. Scopula undivided, covering distal half of metatarsus I and distal third of metatarsi II-III; all tarsi covered with scopula throughout 


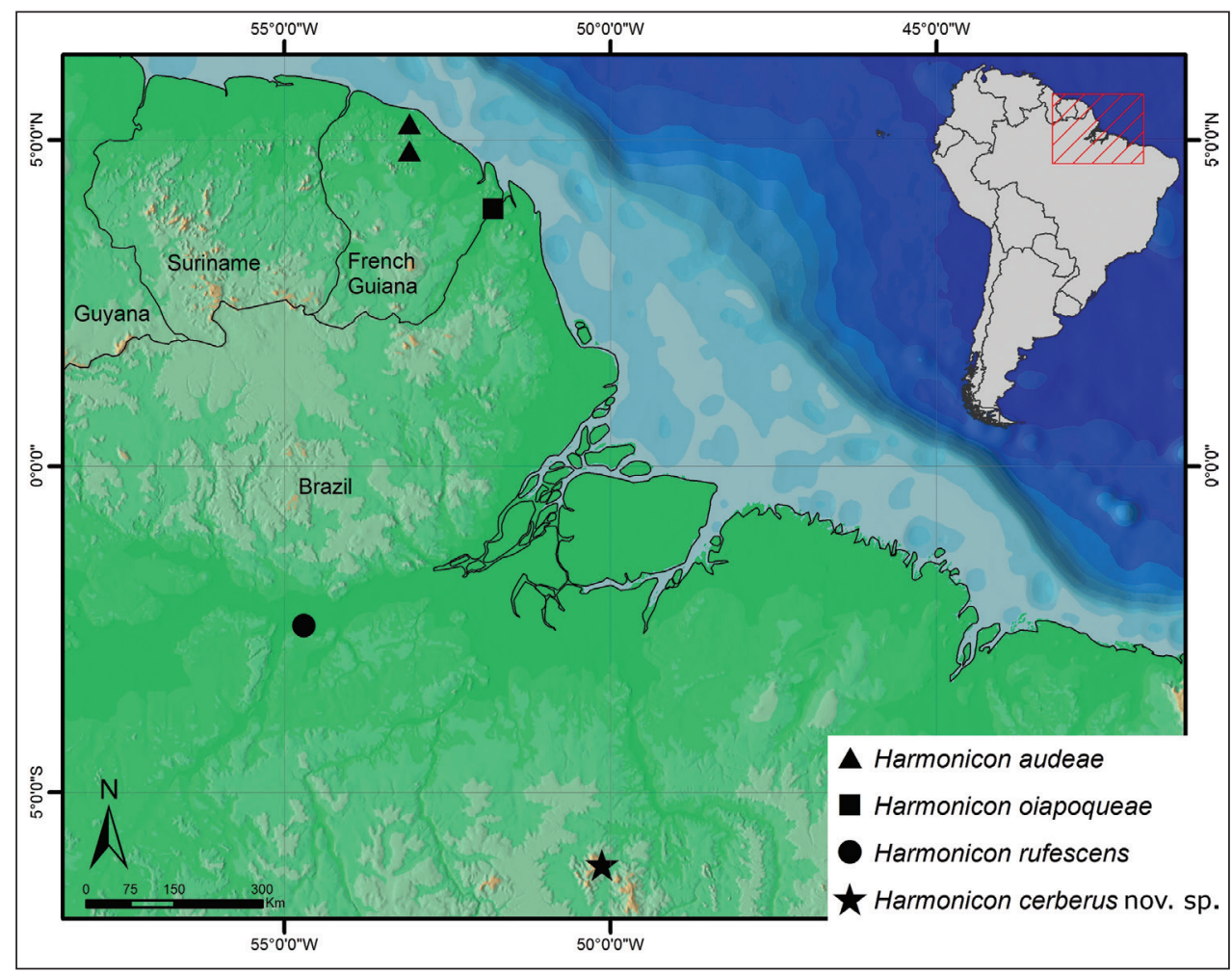

Map I. Distribution map with published records for Harmonicon species.

length. All tarsi flexible, with abundant cracks. Spines: leg I: femur d2-2-0 left, d2-1-0 right, pld0-2-1 left, pld1-1-1 right, rld1-2-1 left, rld1-1-2 right; patella 0; tibia p10-1, r1-0-1 left, r1-0-0 right, v1-1-1ap (apophysis) left, v2-1-1ap (apophysis) right; metatarsus p0-1-0, v1-2-0 left, v1-2-1ap right; leg II: femur d2-2-0 left, d3-1-0 right, pld1-3-1 left, pld1-2-1 right; patella 0; tibia p1-1-1 left, p1-0-1 right, v2-1-1ap left, v1-1-1 ap right; metatarsus pld0-1-0, v1-2-2ap; leg III: femur d2-1-0 left, d3-1-0 right, pld0-2-1, rld1-1-1 left, rld1-2-1 right; patella 0, tibia plv0-1-0 right, pld1-0-1 right, rld1-2-1, v2-2-2ap; metatarsus d2-1-1 left, d1-1-1 right, pld2-2-1 left, pld1-2-0 right, rld1-3-0 left, rld1-3-1 right, v2-1-3ap left, v1-1-2ap right; leg IV: femur d2-1-0, pld12-1 left, pld0-2-1 right, rld2-3-1 left, rld2-1-2 right; patella 0, tibia pld1-1-0 left, pld12-0 right, rld1-2-2(1ap) left, rld1-2-1 right, v2-2-2ap; metatarsus d1-1-1 left, d2-1-0 right, pld2-1-1 left, pld2-2-1 right, rld2-3-2 left, rld1-2-1 right, v2-1-2ap. Claws: ITC without teeth. Teeth at STC: leg I inner row 4-5, outer row 10-13; leg II inner row 4-5, outer row 10-12; leg III inner row 3, outer row 9-11; leg IV inner row 2-3, outer row 7-10. Bulb (Figs 7-9) globose, with moderately long embolus, a little longer than basis (ratio 1,3). Bulb with prolateral face convex, gently and uniformly curved, retrolateral face convex at basis and concave at end portion, due to an abrupt curve, forming a strong constriction of bulb near basis of embolus. Embolus with a broad 
basis, regularly tapering to tip, both in prolateral and retrolateral views. In frontal view, embolus placed at prolateral margin of bulb, slightly curved initially, straight through most of its length, with apex bent retrolaterally (Fig. 9). Also, there is a strong bulge of bulb near embolus basis at same view.

Color pattern (in 75\% ethanol). Carapace pale yellow, with thoracic furrows and cephalic area just a little darker, with orange hue, chelicerae light reddish brown, labium, sternum and leg coxae grayish yellow, sigillae darker, with orange hue, other leg articles brownish yellow. Abdomen grayish yellow, with abundant long, thick black hairs.

Distribution (Map 1). know only from type locality, in southern Pará state, Brazil.

\section{Remarks}

Troglomorphism. The pale body, fused and reduced eyes and the elongated chelicerae (Figs 1-3) observed in H. cerberus sp. n. seem to be troglomorphic. Harmonicon species display usually a highly contrasting color pattern, with a reddish carapace, a black, dark brown or reddish brown abdomen and dark brown legs. Eyes of Harmonicon tipically are without modification, with two large AME, surrounded by distinct ALE, PME and PLE. The retina and pigmentation of the AME are easily seen through the clear crystalline lens. In contrast, the AME of the new species bears a milky crystalline and no trace of a retina or pigmentation are visible behind it. The ALE and AME of the other Harmonicon bear distinct crystalline and spherical lenses. However, ALE, PME and PLE of $H$. cerberus sp. n. are fused, forming an irregular and asymmetrical white macula, covered by a shallow and irregular lens (Fig. 3). To the best of our knowledge, the crescent shaped lateral eye mass is a rare character in spiders. The elongated chelicera (more than $40 \%$ of the length of carapace) is longer than in other species of the genus. The legs and spinnerets are also elongated, but males of $H$. audeae and $H$. oiapoqueae also have similar long legs. An additional possible troglomorphic character is the elongated trichobothria at the leg tarsus. In comparison to other Harmonicon species, the trichobothria of the new species are approximately twice as longer than the covering hairs and clearly visible in lateral view. Furthermore, $H$. cerberus sp. n. seems to bear more unequivocal troglomorphic characteristics compared to Linothele cavicola, the only other cave inhabiting Diplurinae (Goloboff 1994).

This spider may be a troglobitic species, despite the small dimensions of Pequiá cave. Several other troglobitic species have been collected in some of the more than a thousand iron ore caves in Carajás (Piló and Auler 2009, Trajano and Bichuette 2010, Pellegrini and Ferreira 2011). Most of those caves are reduced in size (horizontal projection 20-30 m), but they may be connected by small conduits, due to the porosity and spongiform nature of the iron ore deposits of the area (Piló and Auler 2009).

Pequiá cave and its surroundings have been thoroughly investigated recently (Pedroso, pers. obs.). However, no additional specimens of Harmonicon have been found. On the other hand, only the entrance and the beginning of the lateral tube were investigated (around $1 / 3$ of the cave), as there is a large water pool mixed with abundant 
guano. Unfortunately, the exploration of the terminal portion of the lateral tube of Pequiá cave needs special equipment, such as floaters. This portion appears to be the best candidate for new attempts to find additional specimens of H. cerberus sp. n., as it is farthest away from the mouth and the darkest area of the cave. Other possible areas for exploration are the numerous caves near Pequiá cave, specially Gaviáo cave, a larger cave situated circa $4 \mathrm{~km}$ from Pequiá cave (Magalhães 2012).

Notes on Harmonicon. In their paper on the revalidation of Harmonicon, Maréchal and Marty (1998) proposed a series of diagnostic characters for the genus: leg I longer than IV (leg formula 1423), contrasting with formula 4123 found in Diplura and other Diplurinae; legs longer and thinner than in Diplura; metatarsus I of males without the prolateral knob found in other Diplurinae; lyra formed by only 5 setae, with a flattened and curved tip, compared to Diplura, where it presents more setae, with a different tip.

The diagnosis of Harmonicon is not so clear-cut. Regarding the leg formula, the female of $H$. audeae itself, the species described by Maréchal and Marty (1998), has leg formula 4123, as does the female of $H$. oiapoqueae (Drolshagen and Bäckstam 2011). The males of $H$. audeae and $H$. oiapoqueae do have a leg formula of 1423 . On the other hand, the legs of the male holotype of $H$. cerberus sp. $n$. follow the formula 4123. Furthermore, most Diplurinae males have longer anterior legs, following the formula 1423 (and even 1243), so this character is not reliable for diagnosing Harmonicon.

Another inconsistent character is the absence of the prolateral knob of male metatarsus I. Both $H$. oiapoqueae and $H$. cerberus sp. n. present the cited knob, so its absence may be an autapomorphy of $H$. audeae.

Considering the lyra, the number and shape of the setae are not consistent throughout Diplurinae. Some Diplura species we have examined have lyra with just a few setae (down to 2), sometimes with tip curved and somewhat flattened. The setae tip though is not as curved and flattened as in Harmonicon. Again the number of setae is not a reliable character for Harmonicon, as already suggested by Drolshagen and Bäckstam (2011).

Additional diagnostic characters for Harmonicon were proposed by Drolshagen and Bäckstam (2011): presence of dense scopula in more than the apical third of pedipalpal tarsus, presence of scopula in the apical third of most leg metatarsi, and leg tarsi "pseudosegmented" (instead of showing only a few cracks). The dense scopula in legs is similar to that found in Trechona, where it is very dense. In Diplura, the scopula is thin, sometimes not conspicuous at all.

The presence of additional, rigid, and somewhat thickened, setae situated distally to the lyra (Fig. 6) may be diagnostic for Harmonicon or at least most of its species. Besides $H$. cerberus sp. n., these setae are found in specimens of $H$. rufescens from Altamira (unpublished data), H. oiapoqueae (see a picture on the website of Drolshagen 2013) and several undescribed species from Brazil. However, an undescribed Harmonicon from Mato Grosso lacks these setae altogether. No such setae were found in all other species of Diplurinae genera we examined.

Some additional characters may prove to be diagnostic, at least in relation to Diplura. The longer tibia of the male pedipalp may distinguish Harmonicon from 
Diplura species, in which tibia are usually short and stout. Long and relatively thin tibia are found also in the diplurines Trechona (ex. Pedroso and Baptista 2004, Pedroso et al. 2008) and Linothele Karsch, 1879 (ex. Paz and Raven 1990). The copulatory bulb of males of most Harmonicon is also remarkably similar to Trechona species (ex. Pedroso and Baptista 2004, Pedroso et al. 2008), with an enlarged basal portion and an elongated embolus.

The legs and palp with denser and longer scopula, the longer tibia of the male palp and the flexible, highly cracked tarsi may indicate a closer relationship between Harmonicon, Trechona, and perhaps Linothele. Another common trait of these genera is the increased body size, compared to Diplura. Compared to Trechona, some easily seen diagnostic characters of Harmonicon are the lyra composed by less than ten setae (vs. complex lyra, with more than 50 setae in several layers) and the absence of the chevron pattern on the abdomen (vs. presence).

All the published records for described Harmonicon species are located in the northeastern Amazon region, from northern French Guiana to central Pará state, Brazil (Map 1). The type locality of H. cerberus sp. $\mathrm{n}$. is the southernmost record for the genus, located in southern Pará state. However, we examined specimens of several Harmonicon species covering a much larger area, ranging from Peru in the west, to states in northeastern (Bahia, Ceará) and central (Mato Grosso, Goiás) regions in Brazil.

\section{Acknowledgments}

We are grateful to Gustavo Silva de Miranda (MNRJ) for help with the map and to Pedro de Souza Castanheira for help during the description process. This work was supported by a Ph.D. grant from Fundação de Amparo à Pesquisa do Estado do Rio de Janeiro (FAPERJ).

\section{References}

Bertani R, Bichuette ME, Pedroso DR (2013) Tmesiphantes hypogeus sp. nov. (Araneae, Theraphosidae), the first troglobitic tarantula from Brazil. Anais da Academia Brasileira de Ciências 85(1): 107-115. doi: 10.1590/S0001-37652013005000007, http://www.scielo. br/pdf/aabc/2013nahead/0001-3765-aabc-0713.pdf

Coyle F (1988) A revision of the American funnel-web mygalomorph spider genus Euagrus (Araneae, Dipluridae). Bulletin of the American Museum of Natural History 187(3): 203-292. http://hdl.handle.net/2246/924

Cunha Jr WR, Atzingen NV, Crescencio G (2007) Estudos espelológicos na serra dos Carajás, município de Parauapebas-PA. Anais do XXIX Congresso Brasileiro de Espeleologia [Ouro Preto] 1: 97-103.

Drolshagen B (2013) Dipluridae Wiki. http://www.dipluridae.de/wiki/index.php/Main_Page [accessed August 29, 2013] 
Drolshagen B, Bäckstam CM (2011) Notes on the genus Harmonicon F.O.P.-Cambridge, 1896 (Araneae, Dipluridae) with description of a new species from French Guyana. ZooKeys 112: 89-96. doi: 10.3897/zookeys.112.1205

GEONAMES (2013) GeoNames. http://www.geonames.org/ [accessed August 29, 2013]

Goloboff PA (1994) Linothele cavicola, a new diplurine spiders (Araneae, Dipluridae) from caves in Ecuador. Journal of Arachnology 22: 70-72. http://www.jstor.org/discover/10.23 07/3705713 ?uid $=37623 \&$ uid $=3737664 \&$ uid $=5909624 \&$ uid $=2 \&$ uid $=3 \&$ uid $=37622 \&$ ui $\mathrm{d}=67 \&$ uid $=62 \&$ sid $=21103001099951$

Hadley A (2013) CombineZP News. http://www.hadleyweb.pwp.blueyonder.co.uk/CZP/ News.htm [accessed August 29, 2013]

IBAMA (2003) Plano de Manejo para Uso Múltiplo da Floresta Nacional de Carajás. MMA, Brasília, 213 pp. http://www.icmbio.gov.br/portal/images/Carajas.pdf

IPHAN (2013) Cadastro Nacional de Sítios Arqueológicos. http://www.iphan.gov.br/sgpa/ cnsa_detalhes.php?5634 [accessed August 21, 2013]

Magalhães MP (2012) Evolução Antropomorfa da Amazônia. Revista de História da Arte e Arqueologia [Campinas] 12: 5-38. http://www.unicamp.br/chaa/rhaa/downloads/Revista\%2012\%20-\%20artigo\%201.pdf

Maréchal P, Marty C (1998) Réhabilitation du genre Harmonicon (Pickard-Cambridge, 1896) et description d'une nouvelle espèce de Guyane Française (Araneae, Mygalomorphae, Dipluridae). Zoosystema 20: 499-504. www.mnhn.fr/publication/zoosyst/z98n3a7.html

Paz N, Raven R (1990) A new species of Linothele from Colombia (Araneae, Mygalomorphae, Dipluridae). Journal of Arachnology 18: 79-86. http://www.americanarachnology.org/ JoA_free/JoA_v18_n1/JoA_v18_p79.pdf

Pedroso DR, Baptista RLC (2004) Redescription of Trechona venosa (Latreille, 1832) and designation of its neotype (Araneae: Dipluridae). Revista Ibérica de Aracnología [Zaragoza] 10: 149-156. http://www.sea-entomologia.org/Publicaciones/RevistaIbericaAracnologia/ RIA10/R10-014-149.pdf

Pedroso DR, Baptista RLC, Ferreira PSF (2008) Trechona rufa (Araneae, Dipluridae): new status, redescription and neotype designation with notes on the genus. Journal of Arachnology 36: 360-367. doi: 10.1636/CA07-109.1

Pellegrini TG, Ferreira RL (2011) Coarazuphium tapiaguassu (Coleoptera: Carabidae: Zuphiini), a new Brazilian troglobitic beetle, with ultrastructural analysis and ecological considerations. Zootaxa 3116: 47-58. http://www.mapress.com/zootaxa/2011/f/z03116p058f.pdf

Pickard-Cambridge FO (1896) On the Theraphosidae of the lower Amazons: being an account of the new genera and species of this group of spiders discovered during the expedition of the steamship "Faraday" up the river Amazons. Proceedings of the Zoological Society of London 1896: 716-766.

Piló LB, Auler A (2009) Geoespeleologia das cavernas em rochas ferríferas da região de Carajás, PA. Anais do XXX Congresso Brasileiro de Espeleologia [Montes Claros] 1: 181-186. http://www.sbe.com.br/anais31cbe/31cbe_515-520.pdf

Platnick NI (2014) The World Spider Catalog, version 14.5. http://research.amnh.org/entomology/spiders/catalog/index.html [accessed February 15, 2014] 
Prous X, Vasconcellos M, Bezerra T (2011) Contribuição ao conhecimento da biologia de cavernas em litologias ferríferas de Carajás, PA. Anais do XXXI Congresso Brasileiro de Espeleologia [Ponta Grossa] 1: 515-520. http://www.sbe.com.br/anais30cbe/30cbe_181-186.pdf

Raven RJ (1985) The spider infraorder Mygalomorphae (Araneae): Cladistics and systematics. Bulletin of the American Museum of Natural History 182: 1-180. http://hdl.handle. net/2246/955f

Trajano E, Bichuette ME (2010) Diversity of Brazilian subterranean invertebrates, with a list of troglomorphic taxa. Subterranean Biology 7: 1-16. http://www.researchgate.net/publication/221675890 